\title{
Tuning of Operating Conditions in View to Access To a Single Polymorph by Spray Drying
}

\author{
D. Martins ${ }^{\mathrm{a}}$, F. Gouriou ${ }^{\mathrm{b}}$, G. Coquerel $^{\mathrm{a}}$ \\ aUnité de Croissance Cristalline et de Modélisation Moléculaire, Laboratoire SMS, \\ UPRES EA 3233 IRCOF ; Université de Rouen \\ F-76821 Mont Saint Aignan Cedex France \\ ${ }^{b}$ Centre d'Etudes et de Recherche Technologique en Aérothermique et Moteur \\ Avenue de l'Université \\ F-76801Saint Etienne du Rouvray \\ gerard.coquerel@univ-rouen.fr
}

\begin{abstract}
Spray drying is a suitable method for the manufacturing of many pharmaceutical drugs. Ideally, this method leads in one step to a dry solid with the appropriated particle size distribution (PSD) [1], the right polymorph with the desired crystallinity [2]. Moreover, it is implemented in the continuous mode, so a high productivity is a priori accessible. Therefore, when using spray-drying, there is then no need for large vessels. In practice many parameters have an impact on the PSD, the crystallinity and the physical nature of the powder (amorphous, mixture of forms [3], pure form, etc). It is even possible, by tuning the operating conditions such as the nature of the solvent or the solution concentration [4], to crystallize a single polymorphic form. This communication examines some of these parameters and exemplifies their influences on the final product.
\end{abstract}

\author{
Keywords: \\ API Drugs, Spray Drying, Polymorphism
}

\section{INTRODUCTION}

Drying is the process of removing liquid from solids by evaporation. That is the reason why it was first developed and designed for the food industry, and more specifically for dairy farming. During recent years an increasing interest of the pharmaceutical industry for this method has appeared. Indeed, the spray drying method presents numerous advantages, including the possibility to operate in the continuous mode, with both heat-resistant and heat sensitive products. When suitable conditions have been defined, the powder quality remains constant during the drying operation and a high productivity is achievable. Among other advantage, this method leads to a specific particle size and moisture content in one step, and there is no need for the usual sequence of operations: crystallization, filtration, drying and milling (or micronization). This may represent a considerable reduction of production costs.

However, a difficulty appears during the spray drying process of pharmaceutical drugs. Indeed, most of the time, the desire active pharmaceutical ingredients are crystalline compounds and some of these solids are able to crystallise into different packings (associated or not with different conformations). This phenomenon is called "polymorphism" and the access to a particular polymorphic form generally relies on a balance between thermodynamics and kinetics. The crystallization of a metastable polymorphic form is generally achieved by modifying the nucleation and growth parameters, most frequently the solvent and the temperature. Furthermore, polymorphic forms of a compound may exhibit differences in their solubilities, stabilities, and any other physical properties. The substitution of a polymorph by another can therefore lead to a decrease of the drug bioavailability. Consequently, it is mandatory to identify the different polymorphic forms of a compound (but also the amorphous state if it is detectable) and to crystallise solely the desired phase, for the patient care. That is the reason why it is essential to study the impact of the spray drying process on the structural purity of the final product

\section{MATERIALS AND METHODS}

\subsection{Materials}

The spray dryer used all along this study is a Büchi 190 . This is a conventional laboratory dryer designed to test atomisation in a co-current configuration. It means that the spray of the solution and the drying air flow are directed in the same direction. So, the product dissolved in the microdroplets of solution is protected against the hot air flow by the liquid envelope and the enthalpy of vaporization [5]. The solvent evaporation is fast and the temperature in the drying chamber decreases rapidly. Thus, the solidified product is not in contact with the drying hot air, which is the reason why this type of device is preferentially used for the drying of heat-sensitive food products (e.g. dairy products).

This is an Open Access article distributed under the terms of the Creative Commons Attribution-Noncommercial License (http://creativecommons.org/licenses/by-nc/3.0/), which permits unrestricted use, distribution, and reproduction in any noncommercial medium, provided the original work is properly cited. 
The device is also designed to create the optimum conditions for solvent evaporation, and is always composed of the same elements, namely a pump, an atomiser, a heating and dispensing air system, a drying chamber and a collecting powder system, generally a cyclone (Figure 1). The solution is pumped through the atomiser which produces fine droplets into the drying chamber. Two types of atomiser exist: nozzles and rotary atomiser. Atomiser used here is a nozzle system (Tip $=0.7$ $\mathrm{mm}$; Cap $=1.4 \mathrm{~mm}$ ). Besides, the gas mixture used was filtered air, but pure nitrogen can also be used, notably in view to limit the risk of thermal degradation for oxygensensitive products.

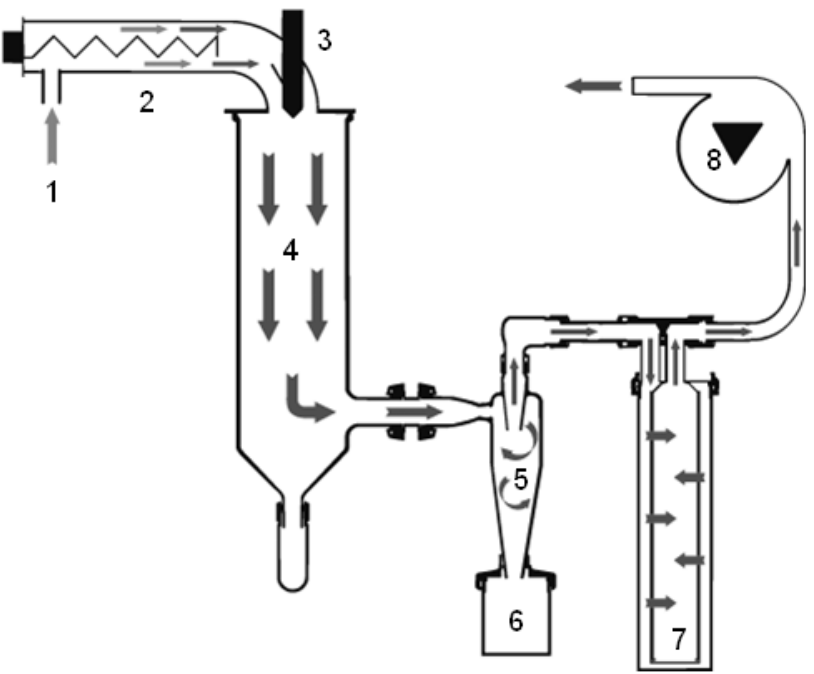

Figure 1: Schematic principle of a spray dryer device with co-current flow. 1 - Dry air (or nitrogen) inlet pipe; 2 Electric resistance; 3 - Atomiser (nozzle system); 4 - Drying chamber; 5 - Cyclone, for the separation of particles and gas; 6 - Bowl collector; 7 - Exit filter (polyester); 8 Aspirator

The parameters under control are: (i) the spray air flow, (ii) the feed rate, (iii) the aspirator flow rate and (iv) the air inlet temperature. These parameters, except for heating, do not have any influence on the produced solid form of the compound. They only impact, to a certain extent, the particle size distribution and the yield. This is the reason why these parameters have been assigned the same value for all experiments: air flow at circa $700 \mathrm{NL} / \mathrm{min}$, feed rate at circa $15 \mathrm{~mL} / \mathrm{min}$ and aspirator flow rate at circa $20 \mathrm{~m}^{3} / \mathrm{h}$. Apparatus specifications of the dryer have been reported in the Table 1.

The main additional parameters influencing the nature of the final phase of the compound are: (1) the nature of the solvent, (2) the drying air inlet temperature and (3) the solid concentration. The impact of these parameters has been studied here by tuning the operating conditions.

\begin{tabular}{|l|c|}
\hline Max temperature of the drying air & $220^{\circ} \mathrm{C}$ \\
\hline $\begin{array}{l}\text { Compressed air for spray flow } \\
\text { (pressure) }\end{array}$ & $5-8$ bar \\
\hline Compressed air consumption & $\operatorname{max~} 1000 \mathrm{NL} / \mathrm{h}$ \\
\hline Evaporation yield & $1 \mathrm{~kg} \mathrm{H} \mathrm{H}_{2} \mathrm{O} / \mathrm{h}$ \\
\hline
\end{tabular}

Table 1: Technical specifications of the Mini Spray Dryer

Preliminary tests on the behaviour of the pharmaceutical compound $A$ under atomization were carried out. $A$ is an active pharmaceutical ingredient for which 3 polymorphic forms have been characterized, labelled Forms 1, 2 and 3.
An enantiotropic relationship was observed between Form 1 and Form 3. Form 1 is considered as the low temperature variety (stable at $\mathrm{T}^{\circ}<140{ }^{\circ} \mathrm{C}$ ) and Form 3 as the hi gh temperature polymorph (stable at $\mathrm{T}^{\circ}>140^{\circ} \mathrm{C}$ ). Form 2 seems to be of monotropic character with reference to form 1 on the one hand $\left(\mathrm{T}^{\circ}<140{ }^{\circ} \mathrm{C}\right)$ and to form 3 on the other hand $\left(\mathrm{T}^{\circ}>140^{\circ} \mathrm{C}\right)$.

Four solvates have also been identified, one with 1,4 dioxane, and three with dimethyl sulfoxide.

The second pharmaceutical compound of this study (pending patent), is labelled compound B. 7 polymorphic forms of this molecule were characterized: Form I, II, III, III', IV, V, and VI. So far no solvate has ever been identified. So, compound B can be spray dried in any volatile solvent without any risk of solvate crystallisation. FII is the stable form of this compound from room temperature to fusion.

\subsection{Method}

Solutions containing the product (with different concentrations) were spray dried using an air inlet temperature above the boiling point of the solvent but below the melting point of the product. This is the more efficient method in view to collect dry powders. In order to characterize the structural nature of these powders, X-ray powder diffraction analyses were carried out on freshly prepared samples.

X-Ray powder diffraction analyses were carried out on a D8 Discover Bruker system (Bruker analytical X-Ray Systems, Karlsruhe, Germany). The instrument is equipped with a X-Ray tube containing a copper anticathode, (40 kV, $40 \mathrm{~mA}$, Ka1 radiation: $1.5406 \AA$, Ka2 radiation: $1.5444 \AA$ ) , a nickel filter and mounted with an angular detector - Lynx eye TM. For these analyses, the scan step was fixed at $\sim 0.04^{\circ}$ with a counting time of $0.5 \mathrm{sec} / \mathrm{step}$ over an angular range $3^{\circ}-30^{\circ}$. The system is monitored with Diffract . plus XRD commander version 2.5.0 software (Copyright (c) Bruker AXS GmbH 200).

Some of the X-Ray powder diffraction analyses were completed by a synchrotron analysis, in view to control the structural purity of certain samples. The synchrotron, based in Grenoble was used (circumference $=628 \mathrm{~m}$, radiation power $=28 \mathrm{GeV}$ ), and analyses were recorded on the CRG-BM2 line $(\lambda=0.621554 \AA$ ) .

\section{RESULTS AND DISCUSSION}

\subsection{Influence of the nature of the solvent}

Since the polymorph of compound A produced by spray drying is sensitive to the nature of the solvent, attempts were performed in acetone, ethanol, methanol, 1,4dioxane, isopropyl alcohol, 4-methyl-2-pentanone, acetonitrile and 2-butanone.

This study has shown that two classes of solvents have to be differentiated. Indeed, Form 2 preferentially crystallizes in non protic solvents like ketones whereas Form 3 is preferentially obtained in protic solvents like alcohols.

The best results, in terms of crystallinity and structural purity (within the resolution limits of the diffractometer, $\approx$ $5 \%$ in mass), were obtained for Form 2 in 1,4-dioxane, whereas pure Form 3 was obtained in ethanol (figure 2). 


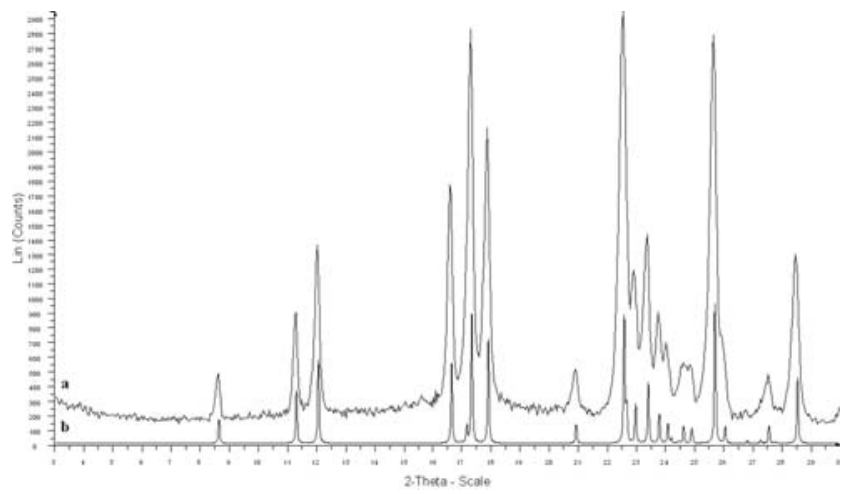

Figure 2: (a) XRPD pattern of spray dried powder of compound $A$ in ethanol, compared to (b) calculated XRPD pattern of compound A Form 3.

It is noteworthy that by using 1,4-dioxane and an hot inlet air flow $\left(130^{\circ} \mathrm{C}\right.$; boiling point $\approx 101^{\circ} \mathrm{C}$ ), the final powder is not the (1,4-dioxane ) 0.5 - the hemisolvate.

It is known that the nature of the solvent used can affect the growth different phases. It can promote one metastable form at the expense of a more stable one $[6,7]$. This has been reported by Khoshkoo and Anwar for sulfathiazole: "the solvent acts by selective adsorption to certain faces of some of the polymorphs, and thereby inhibits their nucleation or retards their growth to the advantage of others" [8]. The spray drying process is a very fast and energetic method of solvent evaporation, out of thermodynamic equilibrium. Therefore, a certain solvent may lead to a metastable form, as a consequence of the Ostwald's rule of stages [9]. Thus, the single reason for the influence of the solvent on the nature of the final phase reported by Khoshkoo and Anwar cannot be sufficient.

By contrast with the previous situation, the solvent has no influence on the nature of the polymorph for compound $B$. Indeed, numerous tests were performed, with a wide variety of solvents, and even with mixtures of solvents, but all experiments led to the metastable Form V. The XRPD analyses carried out on several samples of spray dried powders were confirmed by Synchrotron analyses: freshly produced samples of Form V, obtained by atomization in an acetone solution, is quasi structurally and chemically pure. This metastable phase is particular, because it was demonstrated that all other forms converge toward this variety when undergoing High Energy Milling (HEM) [10]. So Form $\mathrm{V}$ is considered as the dynamic phase under mechanical stress. The swift condition of evaporation brought energy and a sharp increase in pressure during the drying of the spray that can affect the structural nature of the obtained phase.

Hence, it appears that, with a poor degree of predictability, the nature of the solvent can influence the polymorph of the spray dried compound, whereas, in others cases the nature of the solvent does not seem to have any incidence. Besides, the temperature and the concentration of the initial solution can also be used to increase the driving force of the crystallization and to lead to a metastable phase.

\subsection{Influence of the air inlet temperature}

The air (or pure nitrogen) inlet temperature is a key factor of the spray drying process. It corresponds to the temperature of air that permits the solvent evaporation with different rates and affecting the efficiency of the drying.
Thus the crystallization rate is under its influence. In view to confirm the influence of this parameter on the nature of the resulting phase, experiments have been carried out with the pharmaceutical compound $A$. The experiments were performed in acetone, because preliminary tests have shown that Form 2 crystallizes preferentially in this type of non protic solvent, and because acetone has a high vapour pressure $\left(814\right.$ mbar at $\left.50^{\circ} \mathrm{C}\right)$. Thus, it is possible to work at low temperature, even slightly below the boiling point of acetone $\left(B p \approx 56{ }^{\circ} \mathrm{C}\right)$. Concentration of the solution was set at $10 \mathrm{~g} / \mathrm{L}$.

Figure 3 presents the XRPD of the spray dried powders, obtaining in a temperature range between $45^{\circ}$ and $65^{\circ} \mathrm{C}$.

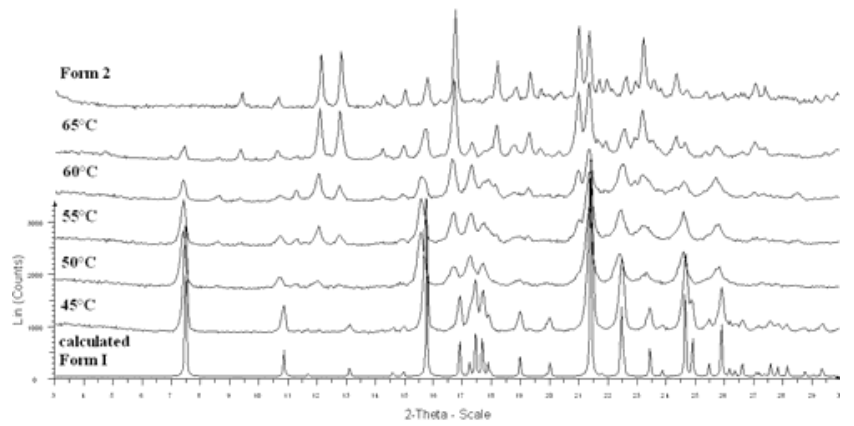

Figure 3: XRPD patterns of spray dried powder obtained by atomisation at $45^{\circ}, 50^{\circ}, 55^{\circ}, 60^{\circ}$ and $65^{\circ} \mathrm{C}$, compare $d$ to the calculated XRPD patterns of the Form 1 and the experimental XRPD of pure Form 2 of the compound A.

The observation of these patterns shows the evolution of the final product versus the air inlet temperature. At the lower temperatures $\left(45^{\circ}\right.$ and $\left.50^{\circ} \mathrm{C}\right)$, diffraction patt erns correspond to calculated XRPD pattern of Form 1. At higher temperatures, peaks of Form 1 decrease to the benefit of those of Form 2. Peaks of Form 2 clearly appear starting at $55^{\circ} \mathrm{C}$, i.e. at the acetone boiling point at room pressure. Intensity of XRPD peaks of Form 2 increase up to $65^{\circ} \mathrm{C}$. Patterns do not evolve when using higher temperatures, even up to $130^{\circ} \mathrm{C}$. A characteristic pea $\mathrm{k}$ of Form 1 is still visible at $2 \theta=7.5^{\circ}$ on all the patterns. The crystallization of the pure Form 2 by spray drying in acetone solution is never achieved, contrary to the atomization in 1,4 dioxane for example.

These results highlight the influence of the drying air inlet temperature on the nature of the final polymorph. The stable form crystallizes preferentially at lower temperatures; this corresponds to the lower solvent evaporation rate. By increasing the kinetics of solvent evaporation, a metastable variety can crystallize preferentially in perfect consistency with the Ostwald rule of stages [9].

\section{CONCLUSION}

This work shows that the crystalline phases of pharmaceutical compounds obtained as a spray dried products is under the influence of several operating parameters. Indeed, these experiments have revealed that solvent and temperature can have an impact on the nature of the polymorph. The results have proved that an adequate choice of the gas inlet temperature and the nature of the solvent give to access to a single polymorph. In others words, it is sometimes possible to "select" the desired solid phase. This confers to spray drying a considerable advantage compare to others methods of production. Indeed, this study reveals that it is possible to 
access to the desired polymorph with: a quantitative yield, a structurally pure form, a good crystallinity, a desirable Particle Size Distribution and without any chemical degradation. A renewed interest for spray drying among pharmaceutical industries is therefore foreseeable.

Other parameters like the concentration of the solution can have an impact on the final product [4]. Preliminary experiments on compound $A$ revealed that as the concentration increases a clear trend toward mixtures of solid forms appears. Extensive tuning tests are in progress.

\section{ACKNOWLEDGMENTS}

The authors would like to thank the CERTAM, especially the "particules et qualité de l'air" team, for its intellectual contribution and financial support.

\section{REFERENCES}

[1] Thanh Huong Hoang Thi, Florence Danède, Marc Descamps, Marie-Pierre Flament, 2008, Comparison of physical and inhalation properties of spray-dried and micronized terbutaline sulphate European Journal of Pharmaceutics and Biopharmaceutics 70, 380-388

[2] 0.I. Corrigan, 1995, Thermal analysis of spray dried products, Thermochimica Acta 248 245-258

[3] Di Martino, P.; Scoppa, M. ; Joiris, E.; Palmieri, G.F.; Andres, C; Pourcelot, Y.; Martelli, S. ; 2001, The spray drying of acetazolamide as method to modify crystal properties and to improve compression behaviour, Int. J. of Pharm. 213, 209-221

[4] Chidavaenzi, O.C.; Buckton, G.; Koosha, F.; Pathak, R.; 1997, The use of thermal techniques to assess the impact of feed concentration on the amorphous content and polymorphic forms present in spray dried lactose; Int. J. of Pharm. 159, 67-74

[5] Reinhard Vehring, 2008, Pharmaceutical Particle Engineering via Spray Drying, Pharmaceutical Research, Vol.25, n5.

[6] Blagden, N.; Davey, R. J.; Lieberman, H. F.; Williams, L; Payne, R.; Roberts, R.; Rowe, R.; and Docherty, R.; 1998, Crystal chemistry and solvent effects in polymorphic systems Sulfathiazole J. Chem. Soc., Faraday Trans., 94(8), 1035-1044.

[7] Threfall, T.; 2000, Crystallization of polymorphs: thermodynamic insight into the role of solvent, Org. Proc. Res. Dev. 4 2000, 384-390.

[8] Khoshkoo, S., Anwar, J.; 1993, Crystallization of polymorphs: the effect of solvent, J. Phys. D: Appl. Phys., Vol 26, B90-B93

[9] Ostwald, W. Z.; 1897, Studies of the formation and transformation of solid substances, Phys. Chem. 22, 289.

[10] Linol, J.; Coquerel, G.; 2009, Simplification of the landscape under high energy milling of molecular solids exhibiting polymorphism, $35^{\text {th }}$ conference on Phase Equilibria, JEEP'09 